\section{Climical a d} MEDICAL, SURGICAL, OBSTETRICAL, AND
THERAPEUTICAL.

\section{A CASE OF DISLOCATION OF THE FIRST PHALANX OF THE THUMB FOR WARDS.}

By Henry E. Haycock, L R.C.P. Edin., M.R.C.S. ENG.

AT 12.30 A.M. on July lst I was called to see G. P-, aged twenty-seven, under-gardener. When driving down a dark lane that night at 11.30 he ran the wheel of the cart against the hedge, and was thrown into the road, the cart falling upon him as he lay. In falling he alighted on his left hand, holding the reins, of course, and with his thumb doubled into the palm. The result was a dislocation of the first phalanx of the thumb forwards. He suffered extreme pain, and the position of the bones was as follows:-The thumb was much shortened, there was a broad and rounded prominence on the dorsal aspect, and a projection on the anterior surface of the member. Having knotted a piece of bandage tightly around the first phalanx, reduction was effected by forcible adduction and flexion of the thumb across the palm to a right angle, followed by dragging the thumb away from the wrist, when it at once returned to its place with a grating sound. Beyond slight stiffness and swelling there was little discomfort afterwards. I might add the man sustained a bad simple fracture of the tibia and fibula as well. The case is of interest from its rarity and the ease with which reduction was accomplished.

Whitwell, Welwyn.

\section{RESULTS OF TREATMENT OF REDUCIBLE HERNIA BY ALCOHOLIC INJECTIONS.}

\section{By TheODORE ZANGGER, M.D.}

THE original modus operandi of Schwalbe, who introduced this form of treatment in 1871, is slightly modified by Dr. Steffen of Regensdorf (Zurich). A 70 per cent. solution of alcohol was used, and from two to four grammes of this fluid were injected round the saccus herniosus (hernial sac) after reposition of the hernia. The treatment was ambulatory; first one or two injections a week were made, then at greater intervals. Before being dismissed from medical supervision the patient had to go without the truss which he used during the treatment. The time of treatment varied from one month to two years and a half, or more. In 293 cases there were 83 (62 per cent.) cures, 6 (48 per cent.) improvements, 9 ( 9 per cent.) of negative results. A cure was considered to have been obtained when, at least one year after dismissal of the patient, the hernia was neither to be seen nor felt during coughing or under intra-abdominal pressure, and when the patients, most of whom belonged to the labouring class, had been at their usual work for six or seven months. In 10 per cent. of the cases dismissed as cured the hernia returned, owing to various causes. The age of the hernia (sit venia verbo) was not without influence as to the result obtained, as will be seen from the following list:-

\begin{tabular}{|c|c|c|c|c|c|c|c|c|}
\hline $\begin{array}{l}\text { Dura } \\
\text { dis }\end{array}$ & $\begin{array}{l}\text { on of } \\
\text { se. }\end{array}$ & & & $\begin{array}{l}\text { No. of } \\
\text { cases. }\end{array}$ & & $\begin{array}{l}\text { No of } \\
\text { cures. }\end{array}$ & & $\begin{array}{l}\text { Per- } \\
\text { centage. }\end{array}$ \\
\hline Ternia & acipiens & & $\ldots$ & 11 & $\ldots$ & 11 & $\ldots$ & 100 \\
\hline Date, a & ew days & & $\cdots$ & 10 & $\ldots$ & 10 & $\ldots$ & 100 \\
\hline Under & year & $\ldots$ & $\ldots$ & 44 & $\ldots$ & 41 & $\ldots$ & $93 \cdot 2$ \\
\hline & & & $\cdots$ & 45 & $\ldots$ & 41 & $\ldots$ & 91 \\
\hline 1 & ," & $\ldots$ & $\ldots$ & 120 & $\ldots$ & 101 & $\ldots$ & $84 \cdot 2$ \\
\hline & 33 & $\cdots$ & $\ldots$ & 52 & $\cdots$ & 34 & $\ldots$ & 4 \\
\hline ver & 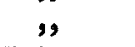 & 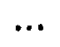 & $\cdots$ & 5 & $\cdots$ & 4 & $\ldots$ & 80 \\
\hline ate $u$ & & & & 6 & & 3 & & 50 \\
\hline
\end{tabular}

Dr. Steffen comes to the following conclusions:-About four-fifths of small and medium-sized reducible herniæ can be cured, the wearing of a truss becoming in most cases superfluous. The prognosis improves the younger the individual, and the shorter the time the hernia has existed. Incipient cases should therefore be treated by injections, and not left to the chance of a spontaneous cure under a truss. Ambulatory treatment, with pauses of from four to seven days, gives better results than daily injection whilst keeping the patient in bed. In most cases the patient does better to continue his usual occupation, wearing a truss during the the time of treatment. This method is also adapted to herniæ which cannot be retained by a truss, the latter being able to be worn, and keeping back the hernia after a course of treatment. In a few cases only toxic effects (alcoholism, urticaria, vertigo) were observed. This method of treatment is not entirely without danger; but accidents will be rare if due care is taken and regard paid to the anatomy of the respective parts. For particulars I must refer to Dr. Steffen's paper in Nos. 12 and 13 of the Correspondenzblat's für Schweizer A erzte. St. Moritz, Engadine.

\section{CASE OF GONORRHCEAL RHEUMATISM.}

By T. CuRtis LemaN, L.R.C.P. Lond., M.R.C.S.

IN the hope that some members of the profession may have met with a similar case, and that they will favour me with their views on the rather sudden fatal termination, $I$ send this case to THE LANCET for publication.

A. B-, young man aged twenty-six. When seen on Sept. lst he was suffering from gonorrhoea, with gonorrhoeal rheumatism complicating, particularly the fibrous structures of the left instep, where he complained of great pain. Heart and lungs normal ; temperature normal, pulse rather feeble tongue very white, but he admitted having been drinking. He was treated for the gonorrhoea by injection, and hot poppy fomentations to the painful instep, the foot to be enveloped in soft tlannel. -Sept. 3rd: When seen, all rheumatic pains had disappeared, but he had developed sym. ptoms of delirium tremens, sleepless and wandering during the night, with hallucinations. Tongue white, temperature normal, pulse feeble; very thirsty, and takes nourishment well. Ordered pills, each composed of a quarter of a grain of morphia hydrochlorate, one to be taken at once, another in six hours if the patient is not quiet. To take beef-tea, with barley water to reliev his thirst, but no stimulants. - Sept. 4th: The first pill had no effect; so in six hours-i.e., at 5 A.M. - he took another, since which time he has been quiet. Taken a good deal of beef-tea during the night, and at midday be regained consciousness for a time, and answered a few questions. Pulse weak ; temperature $101^{\circ}$. Papils respond to light; very restless. From this time he sank into a state of muttering delirium, and died in the evening, despite the administration of stimulants, and before death his temperature ran up to $103^{\circ}$. No post-mortem examination allowed. The question which presented itself to me was whether to attribute his sinking into this form of delirium, followed by death, solely to the delirium tremens, or could the morbid process which had suddenly left the fibrdus structures of various parts of his body have been account. able for his cerebral symptoms?

Chipping Sodbury.

\section{A CASE OF LITHOTOMY.}

By hurand harootune hekimian, M.D.

M. A- came under my observation on Aug. 2nds 1890. He gave a long history of seven or eight years of bladder irritation and dysuria. The patient also called attention to the fact that he had a small fistulous opening somewhere between the rectum and penis, through which opening once quite a large stone had passed.

As a preliminary step the urine was examined, and found full of mucus, with chalky deposits and pus. Apparently the man had been suffering from chronic cystitis and catarrh of the bladder for a long time, with symptoms giving rise to suspicion of stone in the bladder. An external examination revealed that the patient had a large swelling in the perineal region, with a fistulous opening, through which a large stone had once passed ; there was also continual dripping of urine from this point. A rectal examination showed that the swelling was an enormous prostate which was as hard as stone to the touch. On sounding him I found that he had a few strictures along the course of the urethra, which, on inquiry, were the results of a previous attack of gonorrhœa. The sound, while passing with difficulty through the prostatic portion of the urethra, gave 